\title{
Challenging surgical management of failed freestyle stentless porcine valve: two case reports
}

\author{
Parth M. Patel ${ }^{1} \wedge$, Edward P. Chen ${ }^{2}$ \\ ${ }^{1}$ Emory University School of Medicine, Atlanta, Georgia, USA; ${ }^{2}$ Duke University School of Medicine, DUMC 3442, Duke University Medical \\ Center, Durham, North Carolina, USA \\ Correspondence to: Edward P. Chen. Duke University School of Medicine, DUMC 3442, Duke University Medical Center, Durham, North Carolina \\ 27710, USA. Email: edward.p.chen@duke.edu.
}

\begin{abstract}
The Freestyle Stentless Porcine Valve (Medtronic, Fridley, MN, USA) has excellent hemodynamics and can be implanted as either an isolated aortic valve replacement (AVR) or full aortic root replacement. It has excellent durability with documented 15-year freedom data from structural valve degeneration. Open surgical replacement of a failed Freestyle valve, however, can be challenging. Despite minimal calcification of the aortic valve cusps and porcine aortic tissue, there are often dense adhesions between the Freestyle prosthesis and native aortic sinus tissue following a complete subcoronary implantation technique. Valve explant can lead to significant damage to native sinus tissue and typically necessitates an aortic root replacement at the second operation. Herein we present two cases of redo-aortic root replacement following previous Freestyle AVR using the complete subcoronary technique. Patient 1 presented with symptomatic Freestyle regurgitation and patient 2 presented with symptomatic Freestyle stenosis eleven- and nine-years post Freestyle implantation respectively. The case reports describe two different operative interventions. The preoperative work up and perioperative management are also included. Lastly, the unique pitfalls, in our experience, in managing failing Freestyle valves are included. This case report is unique in that it shows a safe and effective means of managing this difficult surgical problem for two different presenting problems. Ultimately the prosthesis of choice after a Freestyle valve explant depends on several factors, including patient preference, tolerance of anticoagulation, as well as other anatomic factors such as root anatomy, and the need for concomitant procedures. However, the operation can be conducted safely and with good outcomes if performed using the techniques described here.
\end{abstract}

Keywords: Freestyle; aortic root replacement; aortic valve replacement (AVR); case report

Received: 28 April 2020; Accepted: 04 December 2020; Published: 20 July 2022.

doi: 10.21037 /jovs-20-121

View this article at: http://dx.doi.org/10.21037/jovs-20-121

\section{Introduction}

The Freestyle Stentless Porcine Valve was first introduced in 1993 (1) as a third generation porcine valve that has both anti-calcification treatment and zero pressure fixation of the aortic cusps. Stentless valves are recognized to provide a large effective orifice area with respect to valve size as well as excellent hemodynamics, and have proven benefit for left ventricular remodeling due to both immediate and lasting excellent valve hemodynamics (2-5). There are multiple options for implanting a Freestyle valve which include an isolated complete subcoronary technique, root inclusion technique, or a full root replacement (6-8).

Surgical replacement of a failed stentless valve has historically been considered a high risk procedure, however recent studies show that reoperation is associated with relatively low morbidity and mortality (9-12). These

^ORCID: 0000-0003-3198-1916. 
Patient 1

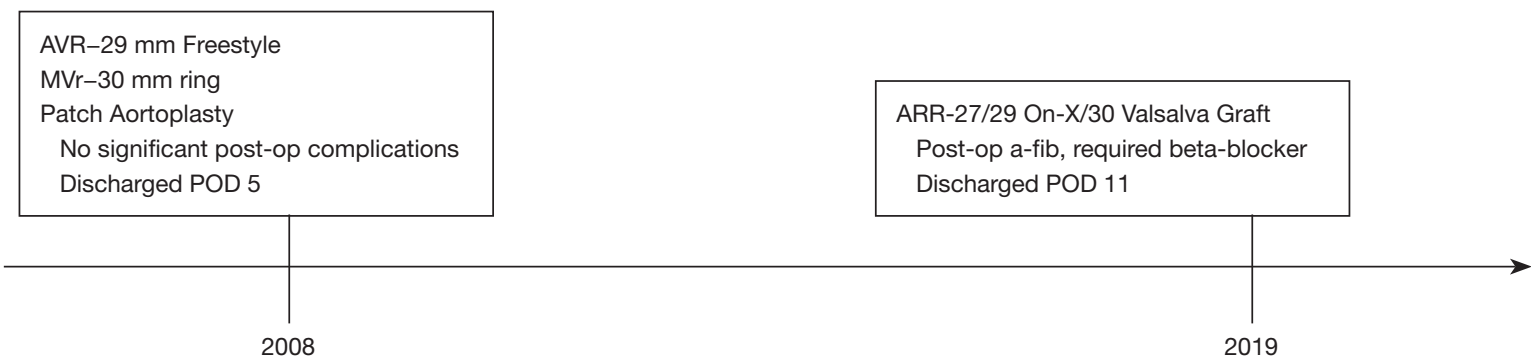

Patient 2

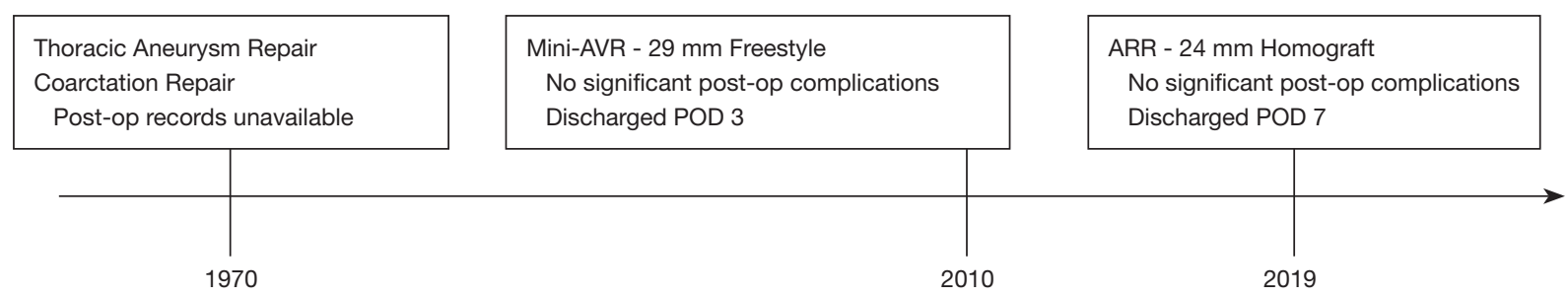

Figure 1 Patient operative timeline. POD, post-operative day; AVR, aortic valve replacement; MVr, mitral valve repair; ARR, aortic root replacement; a-fib, atrial fibrillation.

procedures are considered technically challenging largely due to the dense adhesions between the valve and native sinus tissue as well as the proximity of the aortic root to other critical structures of the heart (9). Freestyle valves most often fail secondary to structural valve degeneration $(10,12,13)$ with endocarditis being the second most common cause $(10,12,13)$.

Reintervention of a failed Freestyle valve can be performed with either transcatheter intervention using a "valve-in-valve" technique or as an open procedure with a full root replacement (11). Isolated aortic valve replacement is also possible and depends on the quality of the native sinus tissue following valve explantation. Some centers report increased mortality with a root replacement, however higher volume centers safely perform a full root replacement for a failed Freestyle valve (11-13).

We present two cases of failed Freestyle valves and outline the surgical management required for optimal outcome. This case report is unique in that it shows a safe and effective means of managing this difficult surgical problem for two different presenting problems. We present the following case in accordance with the CARE reporting checklist (available at https://jovs.amegroups.com/article/ view/10.21037/jovs-20-121/rc).

\section{Case presentation}

All procedures performed in this study were in accordance with the ethical standards of the institutional and/or national research committee(s) and with the Helsinki Declaration (as revised in 2013). Written informed consent was obtained from the patients for publication of this case report and accompanying images. A copy of the written consent is available for review by the editorial office of this journal.

\section{Patient selection and work up}

Patient 1 is a 59 -year-old male former smoker with past medical history of dyslipidemia, hypertension, renal cell cancer status post right nephrectomy, and atrial fibrillation status post cardioversion. In 2008 he underwent aortic valve replacement with a $29 \mathrm{~mm}$ Freestyle valve using the complete subcoronary technique, mitral valve repair ( $\mathrm{P} 1$ resection, $30 \mathrm{~mm}$ ring), and patch aortoplasty for severe bicuspid aortic valve stenosis, moderate to severe mitral regurgitation, and calcific erosion of his aortic root. $\mathrm{He}$ recently presented with a 3-month history of shortness of breath with minimal exertion 11 years after his initial operation (Figure 1). Preoperative work up revealed partial valve dehiscence at the superior margin of the Freestyle valve with severe perivalvular regurgitation with a left ventricular ejection fraction (LVEF) of $55-60 \%$ on transthoracic echo (TTE) (Videos 1,2). The mitral valve had mild regurgitation and there were no other abnormalities 


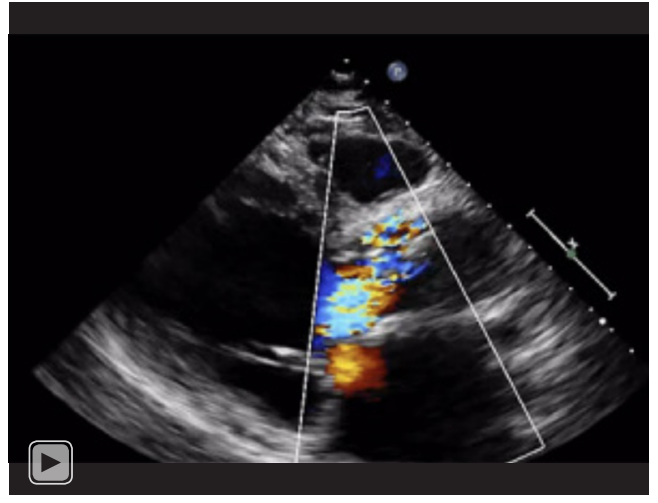

Video 1 This video shows the transthoracic echocardiography of the left ventricular outflow tract of patient 1 with color doppler.

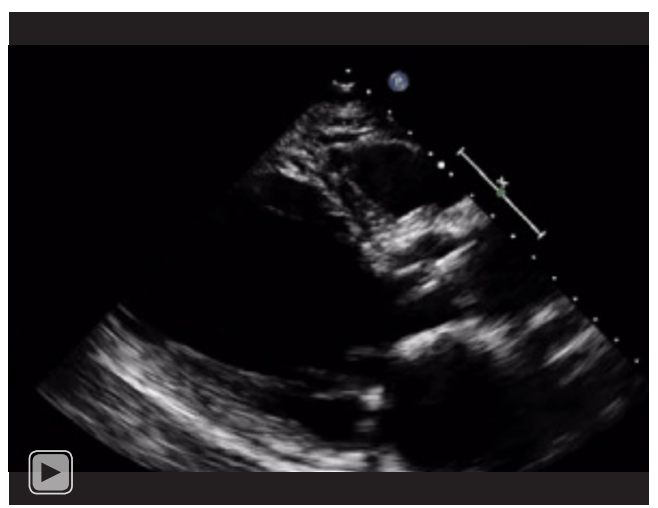

Video 2 This video shows the transthoracic echocardiography of the left ventricular outflow tract of patient 1 without color doppler.

noted. Preoperative labs showed a baseline creatinine of $1.12 \mathrm{mg} / \mathrm{dL}$. All other work up was within normal limits. The patient was adamant about avoiding a third operation. Based on the workup and his wishes, the patient was offered an aortic root replacement with mechanical valve conduit.

Patient 2 is a 57 -year-old former smoker with a past medical history of chronic obstructive lung disease, hepatitis C, hypothyroidism, descending thoracic aortic aneurysm, and coarctation repair at age 8 who had undergone minimally invasive aortic valve replacement with a $29 \mathrm{~mm}$ Freestyle Bioprosthesis (subcoronary technique) for severe bicuspid aortic valve regurgitation in 2010. He presented with 1-year history of worsening shortness of breath, occurring during routine activities which was accompanied with chest pain and some dizziness (Figure 1). Preoperative work up revealed moderate to severe aortic stenosis, with

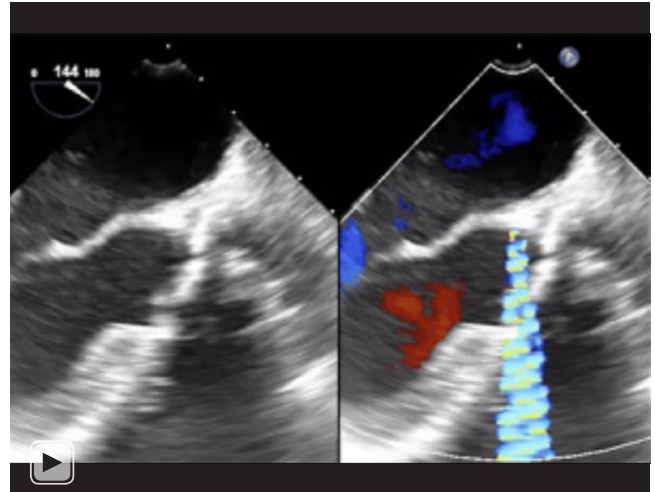

Video 3 This video shows the transthoracic echocardiography of the left ventricular outflow tract of patient 2 with color doppler.

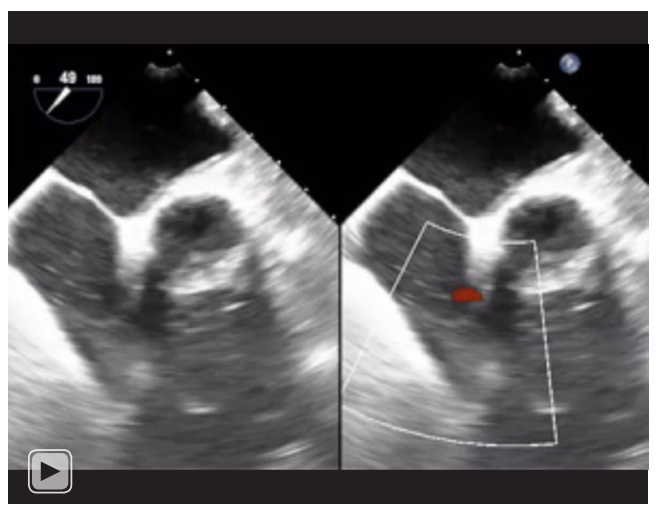

Video 4 This video shows the transthoracic echocardiography of the left ventricular outflow tract of patient 2 with color doppler.

a peak/mean aortic valve gradient of $55 / 32 \mathrm{mmHg}$ and aortic valve area of $0.85 \mathrm{~cm}^{2}$ on TTE (Video 3,4). His LVEF was $60-65 \%$ and in addition to mild left ventricular hypertrophy, there was mild mitral regurgitation, mild tricuspid regurgitation, mild right ventricular dilation, and mildly impaired left ventricular filling. CT of the chest, abdomen, and pelvis revealed that the known descending thoracic aortic aneurysm was stable at 4.5 centimeters and no other anatomical abnormalities. Preoperative labs revealed previously undiagnosed chronic kidney disease with a baseline creatinine of $1.4 \mathrm{mg} / \mathrm{dL}$. This patient did not want to be anticoagulated and given the relatively short period of time since his original operation before valve failure, he was offered an aortic root replacement with a homograft root conduit.

When considering surgical options for a failed Freestyle valve, several clinical factors are taken into 
account and include presenting symptoms, past medical and surgical history, general functional status, and heart failure classification. A typical work up always includes electrocardiogram, preoperative labs, chest X-ray, transthoracic echocardiography, left heart catheterization, and CT scan of the chest, abdomen, and pelvis.

\section{Preoperative preparation}

Aside from the extensive preoperative work up and ensuring all appropriate equipment is available for the day of surgery, there is no specific additional preparation.

\section{Equipment preference card}

Besides standard cardiac surgery instruments and equipment, we ensure that the following items are available for use:

(I) Root graft: if a homograft is used, we ensure an appropriately sized conduit is available with a normal functioning valve. Otherwise, a composite valve-graft conduit is used with either a bioprosthetic or mechanical valve (depending on patient preference) and a Gelweave Valsalva Graft (Sulzer Vascutek, Renfreswshire, Scotland).

(II) Ophthalmic cautery and/or aortic punch device: this is necessary for neo sinus coronary ostium reimplantation.

(III) No special sutures are required. 4-0 permanent braided sutures are used for the proximal root suture line and 5-0 prolene sutures are typically used for coronary reimplantation.

(IV) An intra-aortic balloon pump is occasionally required for cardiac support following cardiopulmonary bypass.

\section{Procedure}

We perform this operation under general anesthesia with endotracheal intubation and a pulmonary artery catheter. A redo median sternotomy is performed with an oscillating saw. The patient is heparinized to an activated clotting time of 480 seconds. The aorta and right atrium are cannulated for cardiopulmonary bypass. Epiaortic ultrasound is used to identify an appropriate aortic cannulation site. Cardiac arrest is achieved with high potassium cold blood cardioplegia and myocardial protection is maintained with intermittent direct ostial cardioplegia as well as with retrograde cardioplegia. The aorta is then transected at the level of the sinotubular junction. The root is dissected and freed from surrounding tissue and adhesions. Stay sutures are placed at the commissures to facilitate visualization. The Freestyle valve is identified and removed from the root. If there are dense adhesions, the root tissue is removed as well; often, this is done in a piecemeal fashion. The buttons for the left and right coronary arteries are made and care is taken to avoid injury to the coronary arteries as they are dissected away from the root a few millimeters. The rest of the annulus is fully debrided of the former sewing ring and suture material. The annulus and root are irrigated and flushed thoroughly ensuring that the coronary ostia are protected. The root is then sized, and the appropriate conduit is brought to the field. Interrupted 4-0 nonpledgeted vicryl sutures are placed circumferentially on the annulus and the conduit. The ophthalmic cautery or aortic punch is used to create openings of the neo-sinuses. The coronary ostia are reimplanted with a 5-0 running prolene sutures with the left ostium being sewn in first. Aortic continuity is then reestablished, typically with a 5-0 running prolene. The heart is deaired, the clamp removed, and the patient is weaned from bypass. The patient is decannulated, protamine is given, hemostasis is achieved, and chest tubes and pacing wires are placed. The chest is closed in the standard fashion and the patient transferred to the intensive care unit (ICU).

\section{Patient 1 (Video 5)}

Patient 1 underwent the above described procedure with a few minor differences. Prior to opening of the chest, he had an intra-aortic balloon pump placed. Due to the presence of severe aortic insufficiency, the heart was arrested using retrograde cardioplegia and arrest was maintained with both direct ostial antegrade and retrograde cardioplegia. The Freestyle valve was able to be dissected free of the aortic root but there was significant thinning of the aortic root and annular aortic ectasia, so the native aortic sinus tissue was excised in preparation for aortic root replacement. A sub-aortic membrane was also identified, and also excised. The patient had a selfconstructed mechanical valve conduit implanted using a 27/29 On-X mechanical valve (CryoLife, Kennesaw, GA, USA) and 30 Valsalva Graft. After his initial chest closure, the patient suffered from high chest tube output in the operating room necessitating a controlled re-entry. A small bleed from the right coronary ostium was found and required a 5-0 pledgeted suture. Hemostasis was achieved 


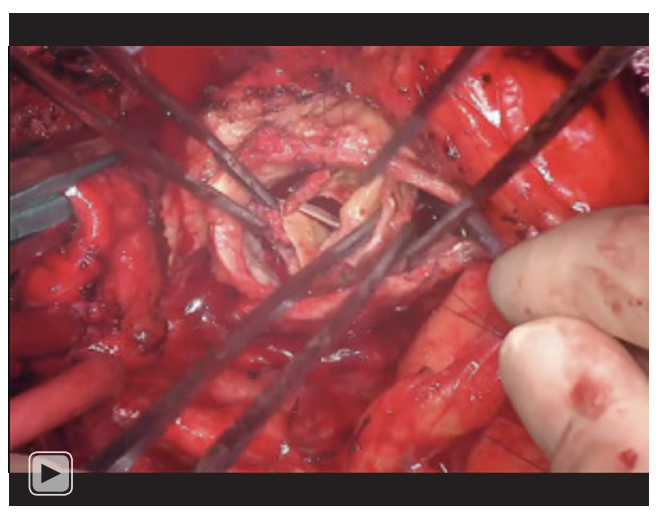

Video 5 This video shows the critical portions of the Freestyle Bioprosthesis explant and aortic root replacement for patient 1 .

again, and the patient was closed and transferred to the ICU. Total cardiopulmonary bypass time of 210 minutes. Total aortic cross clamp time of 182 minutes.

\section{Patient 2 (Video 6)}

Patient 2 underwent the above described procedure. The Freestyle valve was densely adherent to the root necessitating complete excision of the aortic root. He had a $24 \mathrm{~mm}$ homograft root implanted. Total cardiopulmonary bypass time of 183 minutes. Total aortic cross clamp time of 160 minutes.

\section{Role of team members}

(I) Anesthesia team: besides conducting the anesthesia, anesthesia performs and interprets intraoperative transesophageal echocardiography and epiaortic ultrasound. They also collaborate with the surgical and perfusion teams to wean the patient from cardiopulmonary bypass.

(II) Perfusion team: the perfusion team is primarily responsible for the cardiopulmonary bypass machine and maintaining end organ perfusion during the cardiopulmonary bypass time.

(III) Operating room nursing and tech team: the operating room staff ensures that the operating room is ready to accept the patient, ensures all basic cardiac surgery instruments and special instruments requested by the surgeon are readily available, and acts as an additional patient advocate.

(IV) Surgical team: the attending cardiac surgeon oversees the entirety of the patient care, determines the

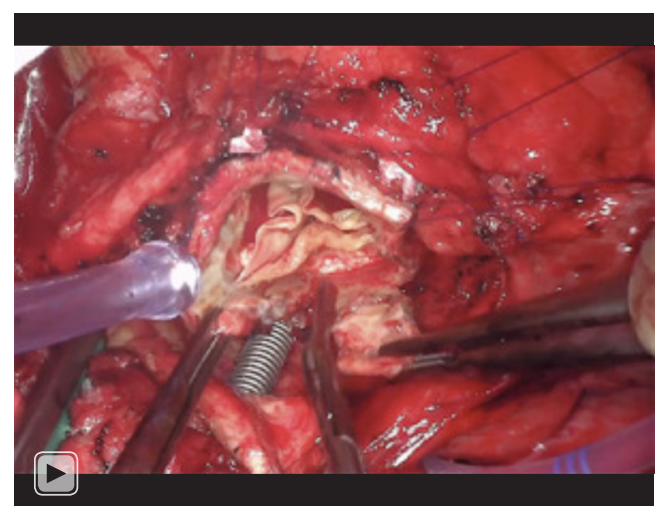

Video 6 This video shows the critical portions of the Freestyle Bioprosthesis explant and aortic root replacement for patient 2.

operation being performed in conjunction with the patient, is responsible for the operative set up, and is present for all critical portions of the case. Resident surgeons are responsible for assisting the attending surgeon and performing parts of the case with close supervision from the attending cardiac surgeon.

(V) Other: team members outside of the operating room are just as critical to an excellent outcome. These team members include the cardiovascular intensive care unit team, dedicated cardiovascular nursing staff, advanced care providers, the cardiology team, and clinic staff members.

\section{Post-operative management}

It is our preference to manage the patient with permissive hypertension initially in their post-operative care, driving the mean arterial pressure to $90 \mathrm{mmHg}$ unless there is concern for bleeding. Additionally, given the significant adhesions and the prolonged cardiopulmonary bypass time, we are aggressive with fluid resuscitation and maintaining an optimal hematocrit in order to optimize end organ perfusion. Using this strategy, our institutional outcomes have been acceptable.

Patient 1 was weaned off all vasoactive medications and extubated the night of the operation. The intra-aortic balloon pump was removed the following morning. The patient went into atrial fibrillation without hemodynamic compromise on postoperative day (POD) 2 which was treated with beta-blockade. The patient was transferred to the floor on POD 3. The rest of his care was uneventful, and the patient was discharged to home on POD 11. At last 
follow up patient 1 is doing well with a well-functioning mechanical aortic valve.

Patient 2 was extubated the night of surgery and was weaned off all vasopressor and inotropic drips by POD 2 . He was transferred to the floor on POD 4. The remainder of his care was uneventful, and he was discharged on POD 7 with a creatinine at baseline of $1.4 \mathrm{mg} / \mathrm{dL}$. At last follow up patient 2 is doing well with a well-functioning homograft.

\section{Discussion}

Surgical intervention for a failed Freestyle valve is a complex and technically demanding operation (9). Current literature from high volume centers estimates 5 years survival of $76-83 \%$ after full root replacement for a failed Freestyle valve (11-13).

Appropriate work-up and robust collaboration with all members of the healthcare team are paramount to ensuring optimal patient outcomes. There is a low threshold to place a preoperative intra-aortic balloon pump due to an anticipated long cardiopulmonary bypass and crossclamp times and complex nature of these operations. Safe dissection of the adhesions surrounding the aortic root without damage to adjacent cardiac structures is critical given its central location.

We find that the safest way to dissect out the aortic root is during cardiopulmonary bypass. On a similar note, removing all foreign material and all abnormal sinus tissue as well as previous suture material prior to sizing the new valve-conduit and placing sutures allows the surgeon to optimize subsequent root reconstruction.

It is of particular importance to be mindful of damaging the coronary ostia in the setting of reoperative surgery as this can not only extend the procedure, but also have longterm implications for the patient in terms of having an adequate long-term myocardial blood supply. Safe dissection of the coronary ostia and arteries away from the root allows for minimal risk of injury during root debridement as well as easier annular suture placement.

One of the most important aspects of reoperative root replacement is providing adequate myocardial protection, particularly in the setting of what will inevitably be a potentially long cardiopulmonary bypass and cross-clamp period. Our cardioplegia strategy is continuous antegrade cardioplegia directly down the coronary ostia along with retrograde cardioplegia for the duration of the procedure. It is also imperative to be mindful of providing regular doses of cardioplegia to the right ventricle for adequate right ventricular protection. Right ventricular failure can be a common cause of hemodynamic instability in the immediate post-operative period, so adequate protection of the $\mathrm{RV}$ is paramount for a successful outcome.

\section{Strengths and limitations}

This case report describes a safe and effective means to treat a diseased Freestyle prosthetic valve. This is by no means the only way to treat a failed Freestyle valve. Both cases were performed relatively recently and there is not yet long term follow up on these particular patients.

\section{Conclusions}

The Freestyle Stentless Porcine Valve has excellent hemodynamics and durability up to 15 years. However, replacement of a failed Freestyle valve can be challenging and often requires a root replacement. Barring a contraindication to surgical intervention, redo sternotomy with root replacement should be the procedure of choice. However, a standard redo-aortic valve replacement is also a reasonable option if sinus and root integrity is maintained after Freestyle valve explant. Replacement of a failed Freestyle valve can be done safely but requires appropriate patient selection, adequate work-up and team collaboration on behalf of the healthcare providers. A sound surgical technique and preparedness for known complications is critical to patient safety since the dense adhesions of the root and the central location of the root put major cardiac structures at risk during the operation.

\section{Acknowledgments}

Funding: None.

\section{Footnote}

Provenance and Peer Review: This article was commissioned by the Guest Editors (Roberto Di Bartolomeo, Davide Pacini, Mohamad Bashir) for the series "Best Video Presentation Prize for the 10th Postgraduate Course on 'Surgery of the Thoracic Aorta' in Bologna" published in fournal of Visualized Surgery. The article has undergone external peer review.

Reporting Checklist: The authors have completed the CARE reporting checklist. Available at https://jovs.amegroups. 
com/article/view/10.21037/jovs-20-121/rc

Conflicts of Interest: Both authors have completed the ICMJE uniform disclosure form (available at https://jovs. amegroups.com/article/view/10.21037/jovs-20-121/coif). The series "Best Video Presentation Prize for the 10th Postgraduate Course on 'Surgery of the Thoracic Aorta' in Bologna" was commissioned by the editorial office without any funding or sponsorship. EPC reports other from Medtronic, outside the submitted work. The authors have no other conflicts of interest to declare.

Ethical Statement: The authors are accountable for all aspects of the work in ensuring that questions related to the accuracy or integrity of any part of the work are appropriately investigated and resolved. All procedures performed in this study were in accordance with the ethical standards of the institutional and/or national research committee(s) and with the Helsinki Declaration (as revised in 2013). Written informed consent was obtained from the patients for publication of this case report and accompanying images. A copy of the written consent is available for review by the editorial office of this journal.

Open Access Statement: This is an Open Access article distributed in accordance with the Creative Commons Attribution-NonCommercial-NoDerivs 4.0 International License (CC BY-NC-ND 4.0), which permits the noncommercial replication and distribution of the article with the strict proviso that no changes or edits are made and the original work is properly cited (including links to both the formal publication through the relevant DOI and the license). See: https://creativecommons.org/licenses/by-nc-nd/4.0/.

\section{References}

1. Yun KL, Sintek CF, Fletcher AD, et al. Aortic valve replacement with the freestyle stentless bioprosthesis: fiveyear experience. Circulation 1999;100:II17-23.

2. Baur LH, Houdas Y, Peels KH, et al. Stentless bioprostheses have ideal haemodynamics, even in the small

doi: 10.21037/jovs-20-121

Cite this article as: Patel PM, Chen EP. Challenging surgical management of failed freestyle stentless porcine valve: two case reports. J Vis Surg 2022;8:28. aortic root. Int J Card Imaging 2000;16:359-64.

3. Baur LH, Peels K, Braun J, et al. Echocardiographic imaging of stentless aortic valve prostheses.

Echocardiography 2000;17:625-9.

4. Bach DS, Kon ND, Dumesnil JG, et al. Ten-year outcome after aortic valve replacement with the freestyle stentless bioprosthesis. Ann Thorac Surg 2005;80:480-6; discussion 486-7.

5. Kunadian B, Vijayalakshmi K, Thornley AR, et al. Metaanalysis of valve hemodynamics and left ventricular mass regression for stentless versus stented aortic valves. Ann Thorac Surg 2007;84:73-8.

6. Ennker JA, Albert AA, Rosendahl UP, et al. Ten-year experience with stentless aortic valves: full-root versus subcoronary implantation. Ann Thorac Surg 2008;85:44552; discussion 452-3.

7. Kon ND, Westaby S, Amarasena N, et al. Comparison of implantation techniques using freestyle stentless porcine aortic valve. Ann Thorac Surg 1995;59:857-62.

8. Ennker J, Albert A, Ennker IC. Stentless aortic valves. Current aspects. HSR Proc Intensive Care Cardiovasc Anesth 2012;4:77-82.

9. Borger MA, Prasongsukarn K, Armstrong S, et al. Stentless aortic valve reoperations: a surgical challenge. Ann Thorac Surg 2007;84:737-43; discussion 743-4.

10. Böning A, Niemann B, Ennker I, et al. Are aortic valve reoperations after primary replacement with stentless heart valve prostheses more demanding than after stented biological prostheses? Thorac Cardiovasc Surg 2014;62:475-81.

11. Finch J, Roussin I, Pepper J. Failing stentless aortic valves: redo aortic root replacement or valve in a valve? Eur J Cardiothorac Surg 2013;43:495-504.

12. Yang B, Patel HJ, Norton EL, et al. Aortic Valve Reoperation After Stentless Bioprosthesis: Short- and Long-Term Outcomes. Ann Thorac Surg 2018;106:521-5.

13. Schneider AW, Hazekamp MG, Versteegh MIM, et al. Reinterventions after freestyle stentless aortic valve replacement: an assessment of procedural risks. Eur J Cardiothorac Surg 2019;56:1117-23. 